\title{
SORORIN and PLK1 as potential therapeutic targets in malignant pleural mesothelioma
}

\author{
TATSUYA KATO ${ }^{1,2}$, DAIYOON LEE ${ }^{1}$, LICUN WU $^{1}$, PRIYA PATEL ${ }^{1}$, AHN JIN YOUNG $^{1}$, \\ HIRONOBU WADA ${ }^{1}$, HSIN-PEI HU ${ }^{1}$, HIDEKI UJIE ${ }^{1}$, MITSUHITO KAJI ${ }^{3}$, SATOSHI KANO ${ }^{4}$, SHINICHI MATSUGE ${ }^{5}$, \\ HIROMITSU DOMEN $^{2}$, HIROMI KANNO ${ }^{6}$, YUTAKA HATANAKA ${ }^{6}$, KANAKO C. HATANAKA ${ }^{6}$, KICHIZO KAGA ${ }^{2}$, \\ YOSHIRO MATSUI ${ }^{2}$, YOSHIHIRO MATSUNO ${ }^{6}$, MARC DE PERROT ${ }^{1}$ and KAZUHIRO YASUFUKU ${ }^{1}$ \\ ${ }^{1}$ Division of Thoracic Surgery, Toronto General Hospital, University Health Network, Toronto, Canada; \\ ${ }^{2}$ Department of Cardiovascular and Thoracic Surgery, Hokkaido University Graduate School of Medicine, Sapporo; \\ ${ }^{3}$ Department of Thoracic Surgery, Sapporo Minami-sanjo Hospital, Sapporo; Departments of ${ }^{4}$ Pathology, and ${ }^{5}$ Surgery, \\ Kinikyo-Chuo Hospital, Sapporo; ${ }^{6}$ Department of Surgical Pathology, Hokkaido University Hospital, Sapporo, Japan
}

Received May 23, 2016; Accepted July 13, 2016

DOI: 10.3892/ijo.2016.3765

\begin{abstract}
Malignant pleural mesothelioma (MPM) is an aggressive type of cancer of the thoracic cavity commonly associated with asbestos exposure and a high mortality rate. There is a need for new molecular targets for the development of more effective therapies for MPM. Using quantitative reverse-transcriptase polymerase chain reaction (qRT-PCR) and an RNA interference-based screening, we examined the SORORIN gene as potential therapeutic targets for MPM in addition to the $P L K 1$ gene, which is known for kinase of SORORIN. Following in vitro investigation of the effects of target silencing on MPM cells, cell cycle analyses were performed. SORORIN expression was analyzed immunohistochemically using a total of 53 MPM samples on tissue microarray. SORORIN was found to be overexpressed in the majority of clinical MPM samples and human MPM cell lines as determined by qRT-PCR. Gene suppression of each SORORIN and PLK1 led to growth inhibition in MPM cell lines. Knockdown of SORORIN showed an increased number of G2M-phase population and a larger nuclear size, suggesting mitotic arrest. High expression of SORORIN (SORORIN-H) was found in $50.9 \%$ of all the MPM cases, and there is a tendency towards poorer prognosis for the SORORIN-H group but the difference is not significant. Suppression of SORORIN with PLK1 inhibitor BI 6727 showed a combinational growth suppressive effect on MPM cell growth. Given high-dose
\end{abstract}

Correspondence to: Dr Kazuhiro Yasufuku, Division of Thoracic Surgery, Toronto General Hospital, University Health Network 200 Elizabeth St, 9N-957, Toronto, ON M5G2C4, Canada

E-mail: kazuhiro.yasufuku@uhn.ca

Key words: SORORIN, [cell division cycle associated 5 (CDCA5)]; polo like kinase 1 , therapeutic target genes, immunohistochemistry, malignant pleural mesothelioma
PLK1 inhibitor induced drug-related adverse effects in several clinical trials, our results suggest inhibition SORORIN-PLK1 axis may hold promise for the treatment of MPMs.

\section{Introduction}

Malignant pleural mesothelioma (MPM) from exposure to asbestos is an aggressive tumor that arises from mesothelial cells lining the intrathoracic cavities, and its worldwide incidence continues to increase (1). The latency period between the time of initial exposure and diagnosis is approximately 30 years although it ranges from 20 to 50 years, and it will continue to be a health concern globally in the next few decades with the continued use of asbestos in developing countries $(1,2)$. Depending on different etiologies of the disease, MPM can be divided into four types: epithelioid, sarcomatoid, desmoplastic and biphasic, according to the World Health Organization (WHO) classification of pleural tumors (3). MPM patients have poor prognosis and current treatment strategies are limited. The median survival time for the main types (epithelioid, sarcomatoid and biphasic) is only 18, 8 and 11 months, respectively (4-6). Aggressive surgery, screening with proposed biomarkers, advances in modern systemic chemotherapy using the combination of pemetrexed and cisplatin, combination of radiotherapy and chemotherapy regimens as well as combined treatment with preoperative radiation followed by surgery are currently being tested, but their benefits and long-term survival in patients with MPM is still rare (7-9). The absence of major improvements in the survival rate has further facilitated research into identifying new strategies aimed at improving MPM survival. To improve these survival rates, more targeted therapies with reduced toxicity are needed. Investigating molecular analyses of MPM samples has led to novel targeted strategies that inhibit specific key molecules in tumor growth and progression.

We have previously screened for potential molecular targets for diagnosis and/or treatment of advanced lung cancer and MPM by analyzing gene expression using quantitative reverse- 
Table I. The clinicopathological characteristics of patients with malignant pleural mesothelioma (MPM).

\begin{tabular}{lc}
\hline Variables & $\mathrm{N}(\%)$ \\
\hline Gender (Male/female) & $49 / 4(92.5 / 7.5)$ \\
Age, years (mean) & 65.5 \\
& (range, $35-80)$ \\
Histology & \\
Epithelioid & $34(64.2)$ \\
Biphasic & $13(24.5)$ \\
Sarcomatoid & $5(9.4)$ \\
Desmoplastic & $1(1.9)$ \\
Surgical procedure & \\
Extrapleural pleuropneumonectomy (EPP) & $21(39.6)$ \\
Pleural biopsy & $28(52.8)$ \\
Tumor resection of recurrent tumors & $3(5.7)$ \\
Radical pleurectomy & $1(1.9)$ \\
\hline Total & 53 \\
\hline
\end{tabular}

transcriptase polymerase chain reaction (qRT-PCR) and RNA interference (RNAi) techniques $(10,11)$ based on profiles of various databases, such as NCBI-Gene ${ }^{\circledR}$ (http://www.ncbi. nlm.nih.gov/gene), GeneCards ${ }^{\circledR}$ (http://www.genecards.org/), GenomeRNAi ${ }^{\circledR}$ (http://genomernai.dkfz.de/GenomeRNAi//) and CTDatabase ${ }^{\circledR}$ (http://www.cta.lncc.br/). Throughout these screenings, we identified SORORIN [alias: cell division cycle associated 5 (CDCA5)] as a potential candidate target gene for the treatment of MPM. Sororin, a cohesin-interacting protein essential for sister chromatid cohesion, plays a novel role in the resolution of sister chromatid arms by direct interaction with polo like kinase 1 (PLK1) (12).

The aims of the present study were to examine the frequency of transcriptional expression of the SORORIN in addition to PLK1, which is known for kinase of SORORIN, in MPM samples, to investigate their functional roles in MPM cell proliferation by using an RNAi technique, and to assess clinicopathological relationships in MPM by immunohistochemical (IHC) study using tissue microarray (TMA) and to explore the possibilities of these target genes as potential molecular targets for therapeutic agents.

\section{Materials and methods}

Malignant mesothelioma clinical samples and tissue samples. Nine samples were taken from patients with MPMs, including four cases of epithelioid, four biphasic and one sarcomatoid subtypes, with written informed consent at Toronto General Hospital (Toronto, Canada). For TMA analysis, a total of 53 MPM were obtained from patients who underwent surgery at Hokkaido University Hospital and its affiliated hospitals between February 1990 and April 2012. Patient's clinical information was extracted from medical records. The protocol was approved by the appropriate institutional review board of Hokkaido University (no. 012-0136). Detailed information about demography and clinical characteristics are summarized in Table I. Postoperative pathological staging evaluation was demonstrated only in curative operative cases $(n=21)$, showing stage I disease in 1 case, stage II disease in 5 cases, and stage III disease in 15 cases. In all, one patient had T1 disease, 7 patients had T2 disease and 13 patients had T3 disease. A total of 9 patients had N0 disease, 5 patients had N1 disease, and 7 patients had N2 disease (Table II). Histological classification of tumors and stage were performed according to the Union for International Cancer Control (UICC) pathological tumor/node/metastasis (pTNM) classification criteria (13).

Malignant mesothelioma cell lines. The human malignant mesothelioma cell lines used were as follows: NCI-H28,-H226, -H2052 and -H2452 were purchased from the American Type Culture Collection (ATCC; Manassas, VA, USA). All cancer cells were grown in monolayers in RPMI-1640 medium supplemented with $10 \%$ fetal bovine serum (FBS). A human adult normal mesothelial cell line (MES-F) was purchased from Zembio Inc. (Research Triangle Park, NC, USA) and was grown in mesothelial cell growth medium (Zembio). All cell lines were maintained at $37^{\circ} \mathrm{C}$ in atmospheres of humidified air with $5 \% \mathrm{CO}_{2}$.

cDNA sample preparation. Tumor samples from MPM patients with surgery were excised and stored at $-80^{\circ} \mathrm{C}$. QIAzol Lysis reagent (Qiagen, Valencia, CA, USA) and one 5-mm stainless steel bead (Qiagen) were added before homogenizing with a TissueLyser Adapter Set (Qiagen) for $2 \mathrm{~min}$ at $20 \mathrm{~Hz}$. Total RNA was then purified using a miRNeasy Mini kit (Qiagen). The amount and purity were measured using a spectrophotometer (NanoDrop; Thermo Fisher Scientific, Wilmington, DE, USA).

Quantitative RT-PCR analysis. cDNA was synthesized from $2 \mu \mathrm{g}$ total RNA using QuantiTect ${ }^{\circledR}$ reverse transcription kit (Qiagen). The primers were designed as follows: for PLK1, forward primer, 5'-cccctcacagtcctcaataa-3' and reverse primer, 5'-tgtccgaatagtccaccc-3'; for SORORIN, forward primer, 5'-cg ccagagacttggaaatgt- $3^{\prime}$ and reverse primer, 5'-gtttctgtttctcgggt ggt-3'; for actin, beta (ACTB), forward primer, 5'-gaaatcgtgcgtgacattaa-3' and reverse primer, 5'-aaggaaggctggaagagtg-3'. qRT-PCR analysis was performed using LightCycler $480^{\circledR}$ SYBR-Green I Master Ready-to-use hot start reaction mix and LightCycler $480^{\circledR}$ system (Roche, South San Francisco, CA, USA). The thermal cycler conditions were as follows: $5 \mathrm{~min}$ at $95^{\circ} \mathrm{C}$ to denature, 45 cycles at $95^{\circ} \mathrm{C}$ for $10 \mathrm{sec}, 56^{\circ} \mathrm{C}$ for $20 \mathrm{sec}$, and $72^{\circ} \mathrm{C}$ for $10 \mathrm{sec}$ for PCR amplification, and $1 \mathrm{~min}$ at $65^{\circ} \mathrm{C}$ for melting. The threshold cycle value was defined as the value obtained in the PCR cycle when the fluorescence signal increased above the background threshold. PCR reactions were carried out in duplicate.

RNA interference and cell viability assay. All short interference RNA (siRNA) oligonucleotide sequences for PLK1 and SORORIN siRNAs were purchased from Qiagen for this study. AllStar Negative Control siRNA ${ }^{\circledR}$ (Qiagen) were used as the negative control (NC-siRNA). The final concentration of $10 \mathrm{nM}$ of siRNAs was incubated with HiPerFect ${ }^{\circledR}$ Transfection reagent (Qiagen) according to the manufacturer's instructions. The PLK1 inhibitor BI 6727 was purchased from Selleck 
Table II. Associations of SORORIN expression and clinicopathological features in patients with mesothelioma ${ }^{\mathrm{a}}$ ( $\mathrm{n}=21$, curative operative cases only).

\begin{tabular}{|c|c|c|c|c|}
\hline \multirow[b]{2}{*}{ Variables } & \multirow[b]{2}{*}{ No. of cases } & \multicolumn{2}{|c|}{ SORORIN expression } & \multirow[b]{2}{*}{ P-value } \\
\hline & & SORORIN-H $(\mathrm{n}=15)$ & SORORIN-L $(\mathrm{n}=6)$ & \\
\hline \multicolumn{5}{|l|}{ Age (years) } \\
\hline$<60$ & 6 & 3 & 3 & \multirow[t]{2}{*}{0.2906} \\
\hline$\geq 60$ & 15 & 12 & 3 & \\
\hline \multicolumn{5}{|l|}{ Gender } \\
\hline Male & 20 & 14 & 6 & \multirow[t]{2}{*}{$>0.9999$} \\
\hline Female & 1 & 1 & 0 & \\
\hline \multicolumn{5}{|l|}{ pT status } \\
\hline pT1-2 & 8 & 7 & 1 & \multirow[t]{2}{*}{0.3359} \\
\hline pT3 & 13 & 8 & 5 & \\
\hline \multicolumn{5}{|l|}{ pN status } \\
\hline pNO & 9 & 7 & 2 & \multirow[t]{2}{*}{0.6594} \\
\hline pN1-2 & 12 & 8 & 4 & \\
\hline \multicolumn{5}{|l|}{ p-stage } \\
\hline I-II & 6 & 5 & 1 & \multirow[t]{2}{*}{0.6227} \\
\hline III & 15 & 10 & 5 & \\
\hline \multicolumn{5}{|c|}{ Histological classification } \\
\hline Epithelioid & 13 & 11 & 2 & \multirow[t]{4}{*}{0.1462} \\
\hline Biphasic & 8 & 4 & 4 & \\
\hline Sarcomatoid & 0 & 0 & 0 & \\
\hline Desmoplastic & 0 & 0 & 0 & \\
\hline
\end{tabular}

${ }^{\mathrm{a}}$ The pathological tumor/node/metastasis (pTNM) classification was based on the Union for International Cancer Control (UICC) (13). ${ }^{\mathrm{b}} \mathrm{P}-\mathrm{value}$ was analyzed by high-level SORORIN (SORORIN-H) vs. low-level SORORIN (SORORIN-L) expression using the Fisher's exact test.

Chemicals (Houston, TX, USA). The CellTiter96 ${ }^{\circledR}$ AQueous One Solution Cell proliferation assay (Promega, Madison, WI, USA) was used for the evaluation of the number of viable cells according to the manufacturer's instructions, using a microplate spectrophotometer ( $\mu$ Quant; BioTek Instruments, Inc., Winooski, VT, USA). Each experiment was performed in triplicate.

Tissue microarray (TMA) construction and immunohistochemistry (IHC). Archival slides for all the cases were reviewed to select three representative areas for each sample by an experienced pathologist (K.H.). TMA blocks were then constructed using a manual tissue microarrayer (JF-4; Sakura Finetek Japan Co., Ltd., Tokyo, Japan) with a 1.0-mm diameter needle. The finalized array blocks were sliced into $4-\mu \mathrm{m}$-thick sections and mounted on glass slides. To check the histopathological diagnosis and adequacy of tissue sampling, a section from each microarray was stained with regular haematoxylin and eosin (H\&E) and calretinin, and examined by a pathologist (K.H.). SORORIN immunostaining were performed using an automated IHC platform (Autostainer plus; Dako, Glostrup, Denmark). Antigen retrieval was performed in the condition of pH 9.0 for 20 min. The detection kit used was the EnVision ${ }^{\mathrm{TM}}+$ Dual Link (K4063; Dako), incubation with post primary for $60 \mathrm{~min}$ at RT. Anti-SORORIN polyclonal antibody (bs-7717R
CDCA5 Sororin antibody; Acris Antibodies GmbH, Herford, Germany, 1/300) was diluted using mixed antibody diluent (Dako:S2022 Antibody diluent). A polymer-based detection system (EnVision ${ }^{\mathrm{TM}}+$ Dual Link \#K4063) was used with 3',3-Diaminobenzidine (DAB) as the chromogen. The positive controls included a sample of testis, and normal lung and pleural samples were used as negative controls. Slides were dehydrated and placed on coverslips.

Evaluation of immunohistochemical staining and statistical analysis. Digital images of IHC-stained TMA slides were obtained using a whole slide scanner (ScanScope CS, Aperio ePathology; Leica Microsystems, Inc., Richmond Hill, ON, Canada). Annotation of tumor regions on whole slides was performed blinded to clinical follow-up data using Aperio's annotation software (ImageScope Viewing Software: Positive Pixel Count v9.1; Aperio). SORORIN were quantified with IHC scoring, which summated the percentage of area stained at each intensity level multiplied by the weighted intensity reported in other studies (14-16). Initially, the weighted intensity of staining was graded as follows; grade 0 (negative), $1+$ (weak positive), $2+$ (moderate positive), and 3+ (strong positive) according to the Aperio's annotation software. According to the total amount of IHC scores, SORORIN expression was then finally divided into two groups each (the threshold leading 

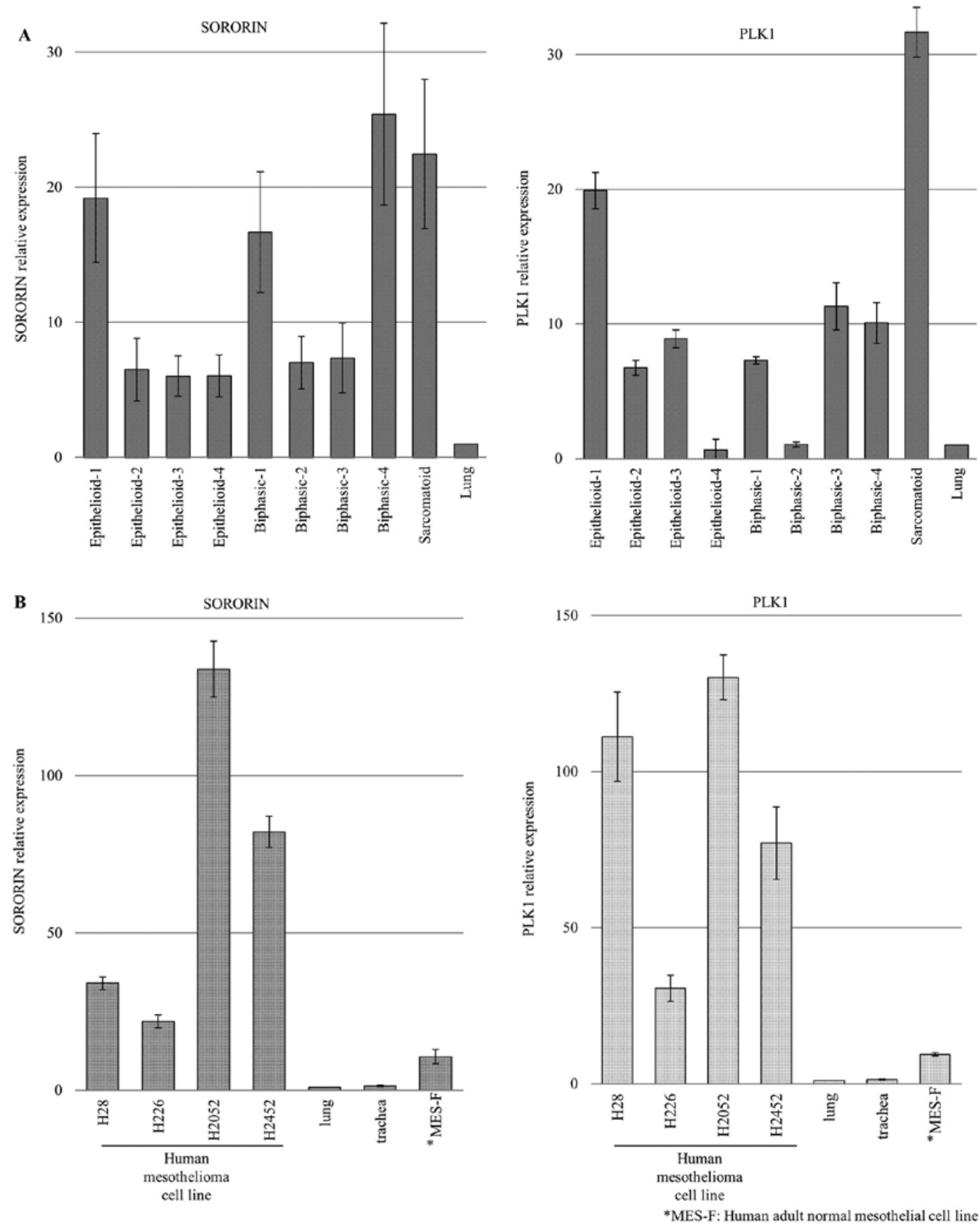

Figure 1. Expression of SORORIN and PLK1 in malignant pleural mesotheliomas (MPMs) by quantitative reverse-transcriptase polymerase chain reaction (qRT-PCR). (A) Expression of the SORORIN and PLK1 genes in MPM clinical samples. The relative gene expression level was normalized to the ACTB level in each sample and calculated as the threshold cycle (CT) value in each sample divided by the CT value in normal lung. Bar represents the mean of duplicate. (B) Expression of the SORORIN and PLK1 genes in human MPM cell lines and human normal mesothelial cell line (MES-F).

to the lowest P-value in log-rank test): low-level SORORIN expression (SORORIN-L, with an IHC score $<1.2$ and highlevel SORORIN expression) (SORORIN-H, with an IHC score $\geq 1.2$ ). We attempted to correlate clinicopathological variables such as age, gender, pathological TNM stage and histological classification with expression levels of SORORIN protein as determined by TMA analysis. Immunoreactivity was assessed for association with clinicopathological variables using the $\chi^{2}$ test for variables. Kaplan-Meier method was used to generate survival curves, and survival differences were analyzed with the log-rank test, based on the status of SORORIN expression. Values of $\mathrm{P}<0.05$ were considered statistically significant.
All analyses were performed using the StatView version 5.0 software (SAS Institute, Inc., Cary, NC, USA).

\section{Results}

Expression of PLK1 and SORORIN transcripts in mesothelioma and normal human tissues. Through qRT-PCR screening for molecular targeted genes in MPMs, we identified SORORIN and PLK1 overexpression in a majority of MPM cases (Fig. 1A). We also confirmed a high expression of these genes using four human MPM cell lines and low expression in a normal human mesothelial cell line MES-F (Fig. 1B). 
A

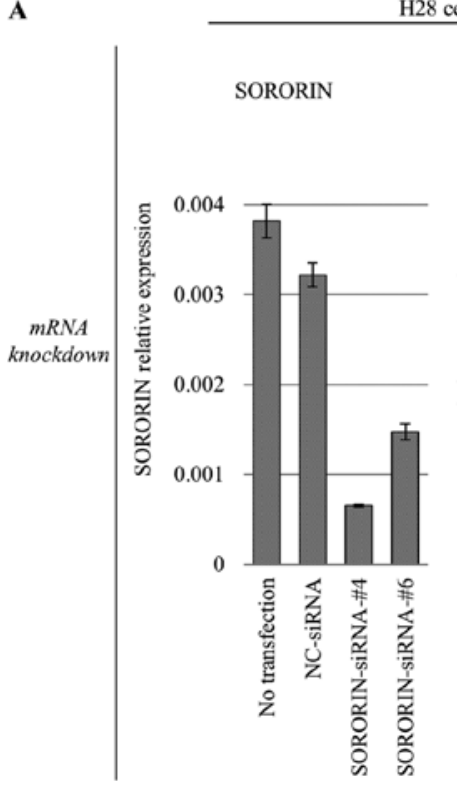

B

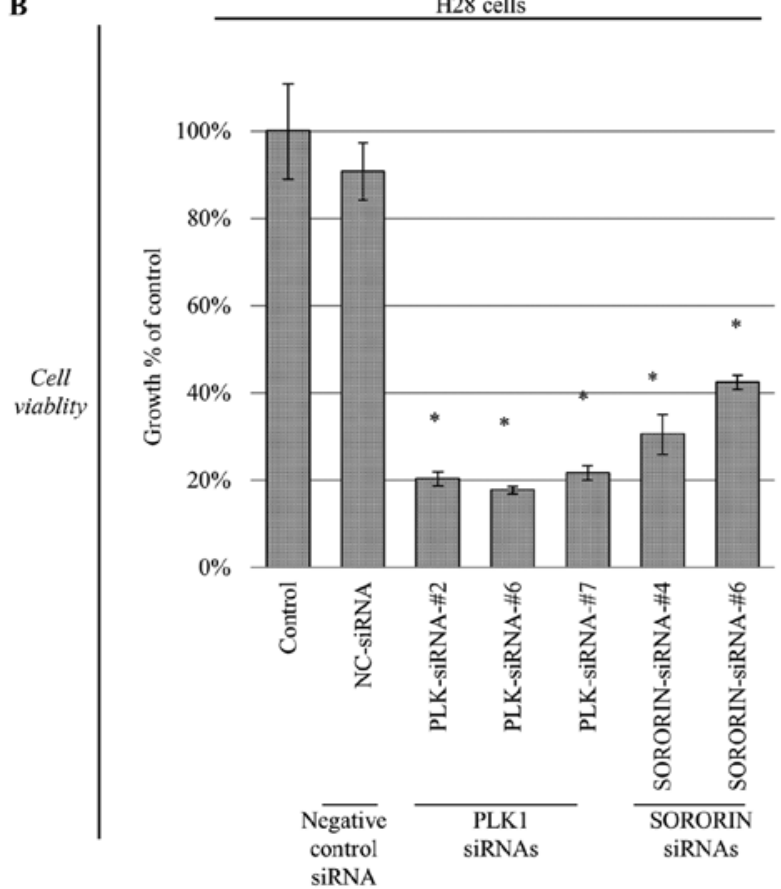

PLK1
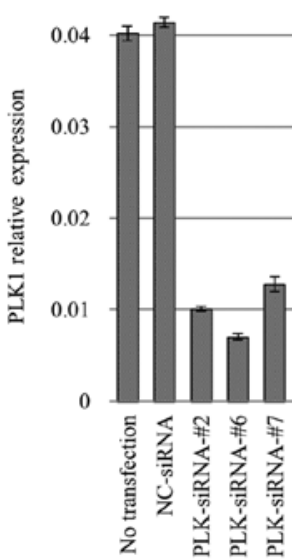

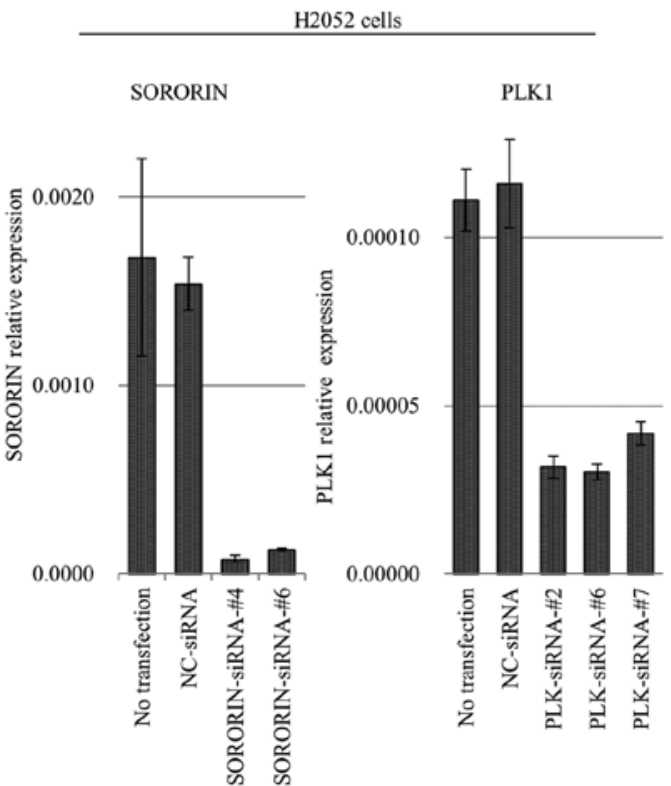

$\mathrm{H} 2052$ cells

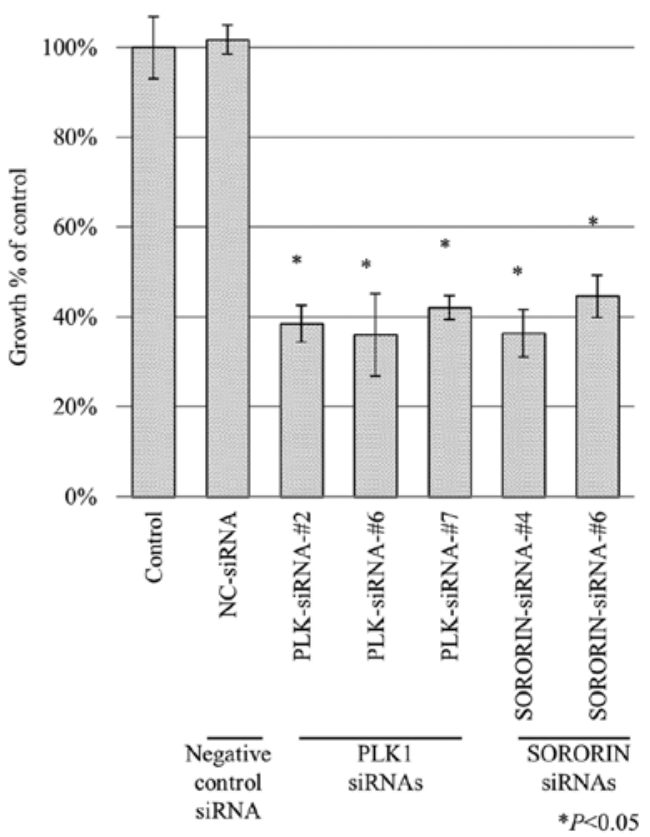

Figure 2. Effects of SORORIN and PLK1 short interfering RNA (siRNA) on human MPM cell proliferation in vitro. (A) qRT-PCR analysis of SORORIN and PLK1 expression in $\mathrm{H} 28$ and $\mathrm{H} 2052$ cells treated with negative control (NC) siRNA, and two different SORORIN- and three PLK1-specific siRNAs for 48 h. Results shown are mean \pm standard deviation (SD) (bars) of duplicates. (B) Effects of SORORIN and PLK1 siRNAs on MPM cell proliferation in vitro: cells were treated with siRNAs for $144 \mathrm{~h}$, and cell viability was determined using a CellTiter96 ${ }^{\circledR}$ AQueous One Solution Cell Proliferation assay. Results shown are mean $\pm \mathrm{SD}$ (bars) of three experiments.

qRT-PCR analysis using a cDNA panel containing normal human tissues also showed that these genes are expressed only in the testis and thymus among the variety of normal human organs (data not shown).

Growth inhibition of mesothelioma cells by specific siRNA against PLK1 and SORORIN. To assess whether therapeutic candidate genes are essential for growth and survival of MPM cells, we transfected each specific siRNA against SORORIN (si-SORORIN-\#4 and si-SORORIN-\#6) and PLK1 (si-PLK1-
\#2, si-PLK1-\#6 and si-PLK1-\#7), into human MPM cell lines $\mathrm{H} 28$ and $\mathrm{H} 2052$ cells, using AllStar siRNA ${ }^{\circledR}$ as the negative control (NC-siRNA). The mRNA level of transfected cells with independent siRNAs targeting these genes was significantly decreased in comparison to cells transfected with control siRNAs $48 \mathrm{~h}$ after transfection (Fig. 2A). Next, to evaluate the relationship between cell proliferation and gene knockdown, we conducted a cell viability assay using the CellTiter $96{ }^{\circledR}$ AQueous One Solution Cell Proliferation assay. After siRNA treatment, proliferation of H28 and H2052 cells 

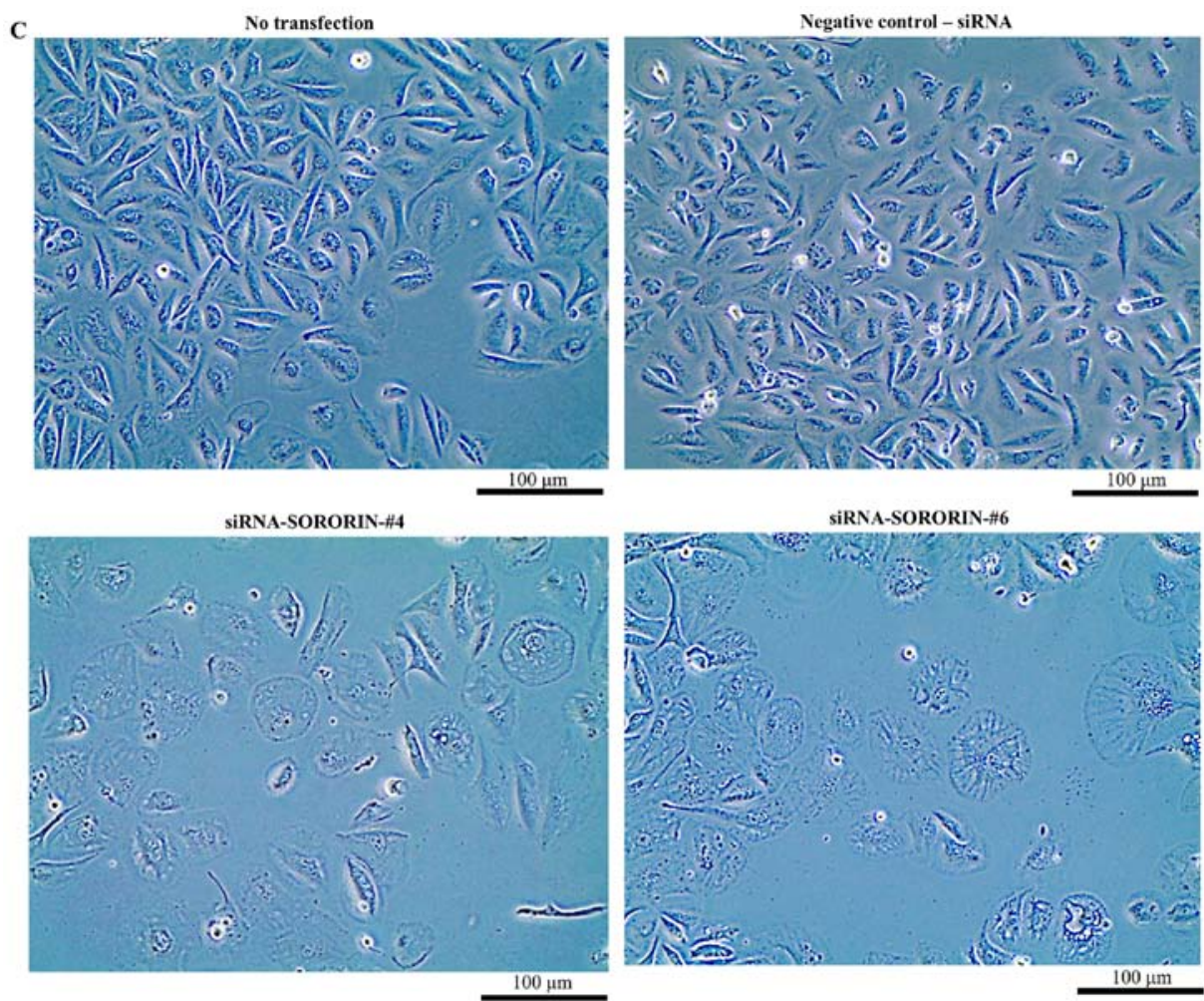

D

H28 cells
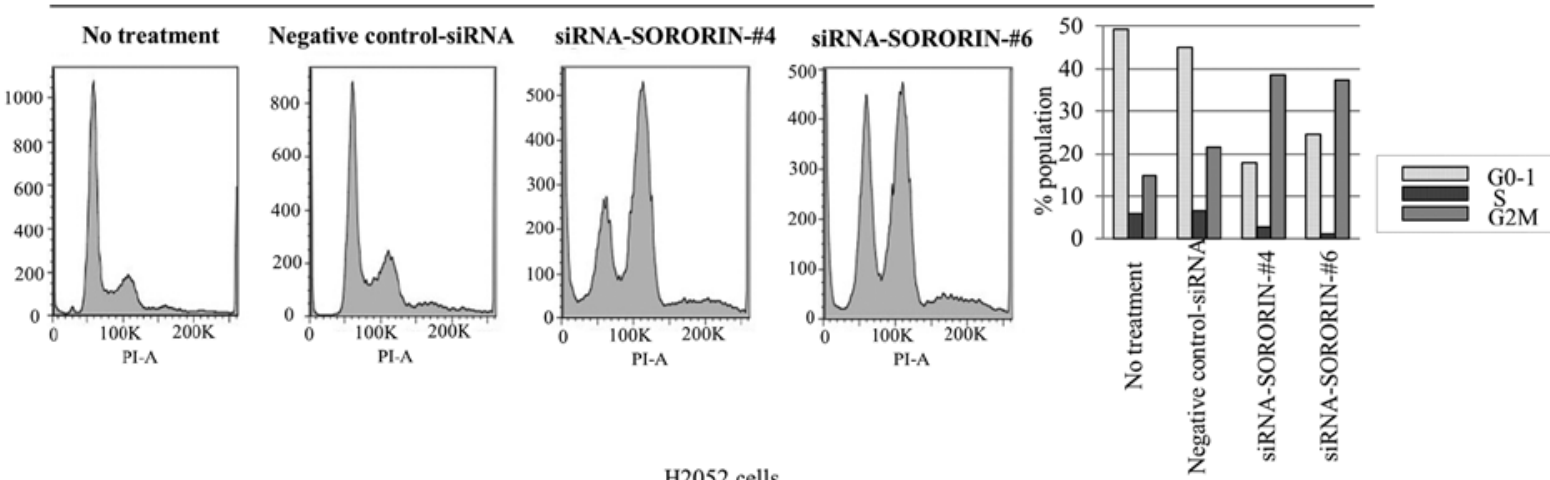

H2052 cells
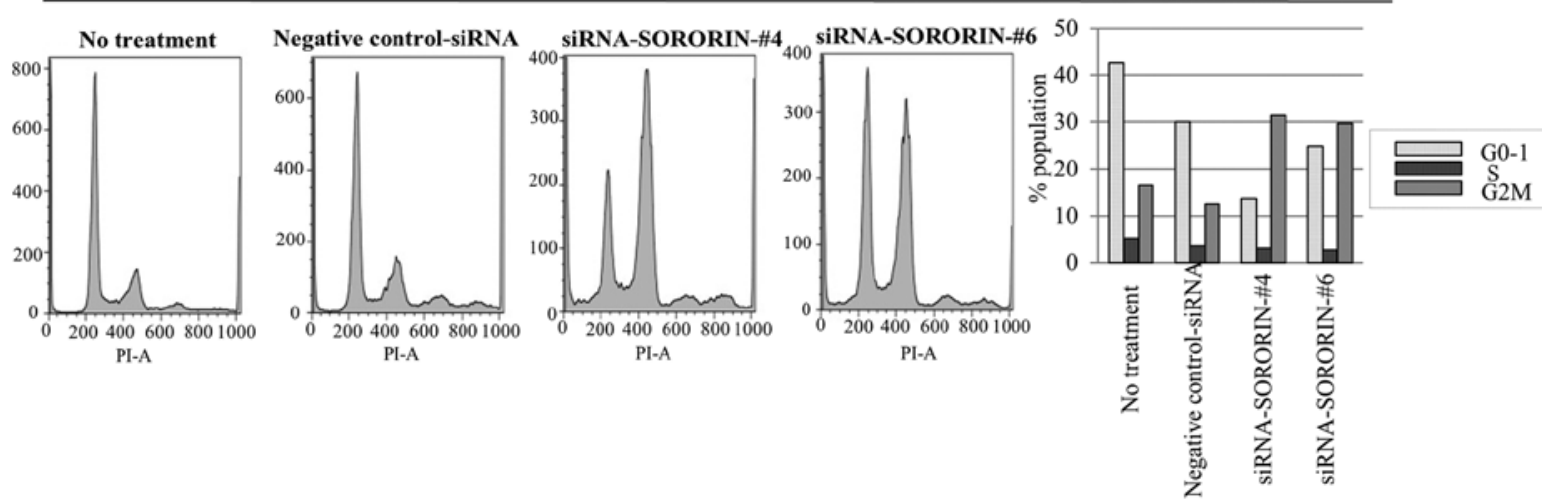

Figure 2. Continued. (C) Effect of SORORIN siRNAs on morphology (H28 cells). Representative micrographs $48 \mathrm{~h}$ after siRNA treatments. (D) H28 and H2052 cells were transfected with NC-siRNA or SORORIN-specific siRNA $(10 \mathrm{nM})$ and cell cycle phases were analyzed by flow cytometry $48 \mathrm{~h}$ post transfection. Representative histograms are shown.

were significantly suppressed compared with control groups at 4 days after transfection (Fig. 2B), suggesting that upregulation of these candidate genes are related to growth or survival of MPM cells. Typical microscopic images of the cells are shown in Fig. 2C. Compared to control cells or negative control siRNA-treated cells, SORORIN siRNA-treated mesothelioma cells exhibited distended cell bodies with enlarged nuclei, suggesting SORORIN-induced mitotic defects. Next, 
Table III. Immunopositivity of SORORIN protein in MPMs ( $\mathrm{n}=53)$.

\begin{tabular}{|c|c|c|c|c|c|c|}
\hline \multirow[b]{2}{*}{ Histology } & \multicolumn{2}{|c|}{$\begin{array}{l}\text { SORORIN low expression } \\
\qquad(\mathrm{n}=26)\end{array}$} & \multicolumn{2}{|c|}{$\begin{array}{l}\text { SORORIN high expression } \\
\qquad(\mathrm{n}=27)\end{array}$} & \multirow[b]{2}{*}{ Total (n) } & \multirow[b]{2}{*}{$\begin{array}{c}\% \text { of high } \\
\text { expression cases }\end{array}$} \\
\hline & $\begin{array}{l}\text { Negative } \\
\text { (IHC score: } \\
-0.599 \text { ) }\end{array}$ & $\begin{array}{c}\text { Weak } \\
\text { (IHC score: } \\
0.600-1.199 \text { ) }\end{array}$ & $\begin{array}{c}\text { Moderate } \\
\text { (IHC score: } \\
1.200-1.799 \text { ) }\end{array}$ & $\begin{array}{c}\text { Strong } \\
\text { (IHC score: } \\
1.800-\text { ) }\end{array}$ & & \\
\hline Epithelioid & 8 & 9 & 9 & 8 & 34 & 50.0 \\
\hline Biphasic & 2 & 3 & 5 & 3 & 13 & 61.5 \\
\hline Sarcomatoid & 2 & 1 & 1 & 1 & 5 & 40.0 \\
\hline Desmoplastic & 1 & 0 & 0 & 0 & 1 & 0.0 \\
\hline Total & 13 & 13 & 15 & 12 & 53 & 50.9 \\
\hline
\end{tabular}

A Malignant pleural mesothelioma (MPM) Benign lesion

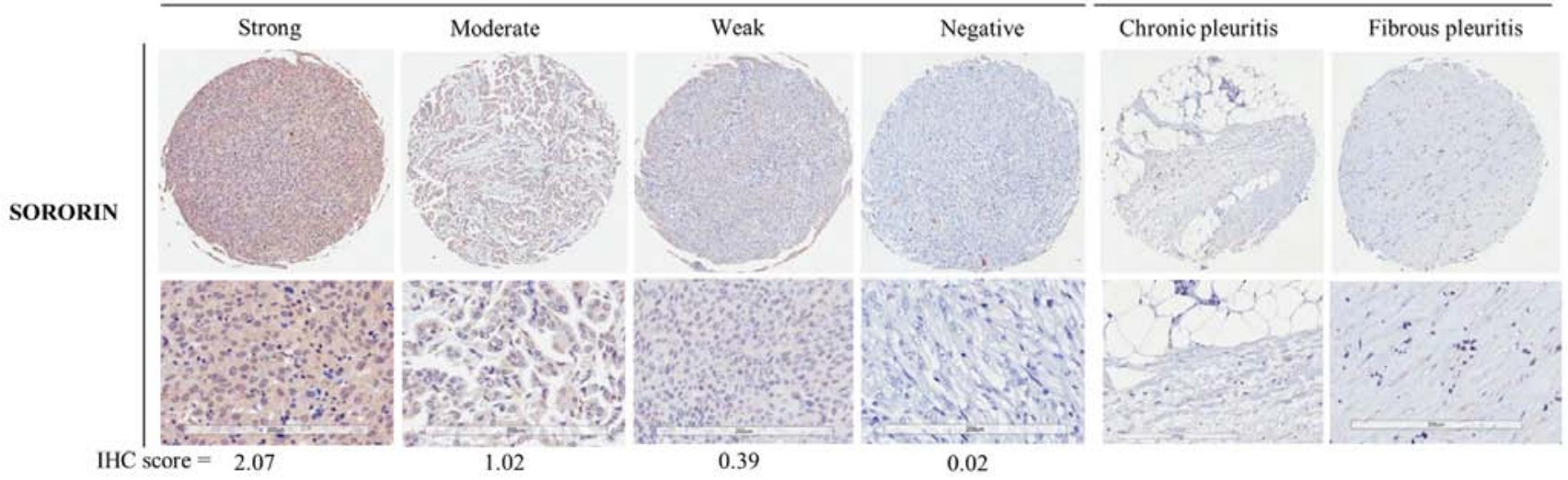

B

SORORIN overall survival

for curative resection (EPP) cases

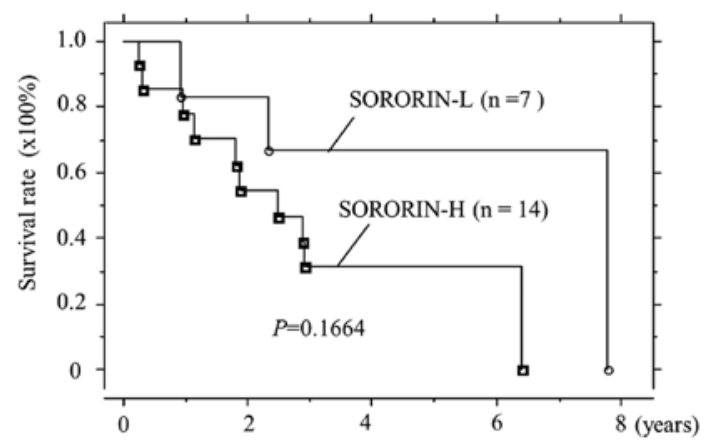

Figure 3. Staining patterns and intensities for SORORIN expression in MPM clinical samples and overall survival curves for MPM patients by IHC-score. (A) Representative examples of SORORIN expression in MPMs. Intensity and proportion were multiplied together to obtain the immunohistochemical (IHC) score (each scores are indicated as below). No SORORIN staining was observed in chronic pleuritis. (B) Kaplan-Meier analysis of overall survival in MPM patients who received curative resection (EPP; extrapleural pleuropneumonectomy) according to SORORIN expression level.

we sought to determine how inhibition of SORORIN causes the observed proliferation defect. The cell cycle distribution was analyzed by flow cytometry. We found that the G2/M population was remarkably elevated in siRNA against SORORIN-treated cells, suggesting a potential increase in the number of mitotic cells (Fig. 2D). These results demonstrate that inhibition of SORORIN induced mitotic arrest, resulting in a defect in cell cycle progression in mesothelioma cells.

Pattern of PLK1 and SORORIN expression in MPMs and correlation to clinicopathological parameters and prognostic significance. We categorized SORORIN expression on the TMA according to the IHC score described above. Positive staining of tumor cells by SORORIN generally showed a nuclear and cytoplasmic pattern in cancer tissue (Fig. 3A). No staining was observed in benign chronic or fibrous pleuritis. Of the 53 MPM cases examined, SORORIN-H was observed in 27 cases $(50.9 \%)$ (details are shown in Table III). Of those, 17 epithelioid type (50.0\% of 34 cases), 8 biphasic type $(61.5 \%$ of 13 cases) and 2 sarcomatoid type ( $40.0 \%$ of 5 cases) showed SORORIN-H. We then tried to correlate SORORIN expression with various clinicopathological parameters. When 

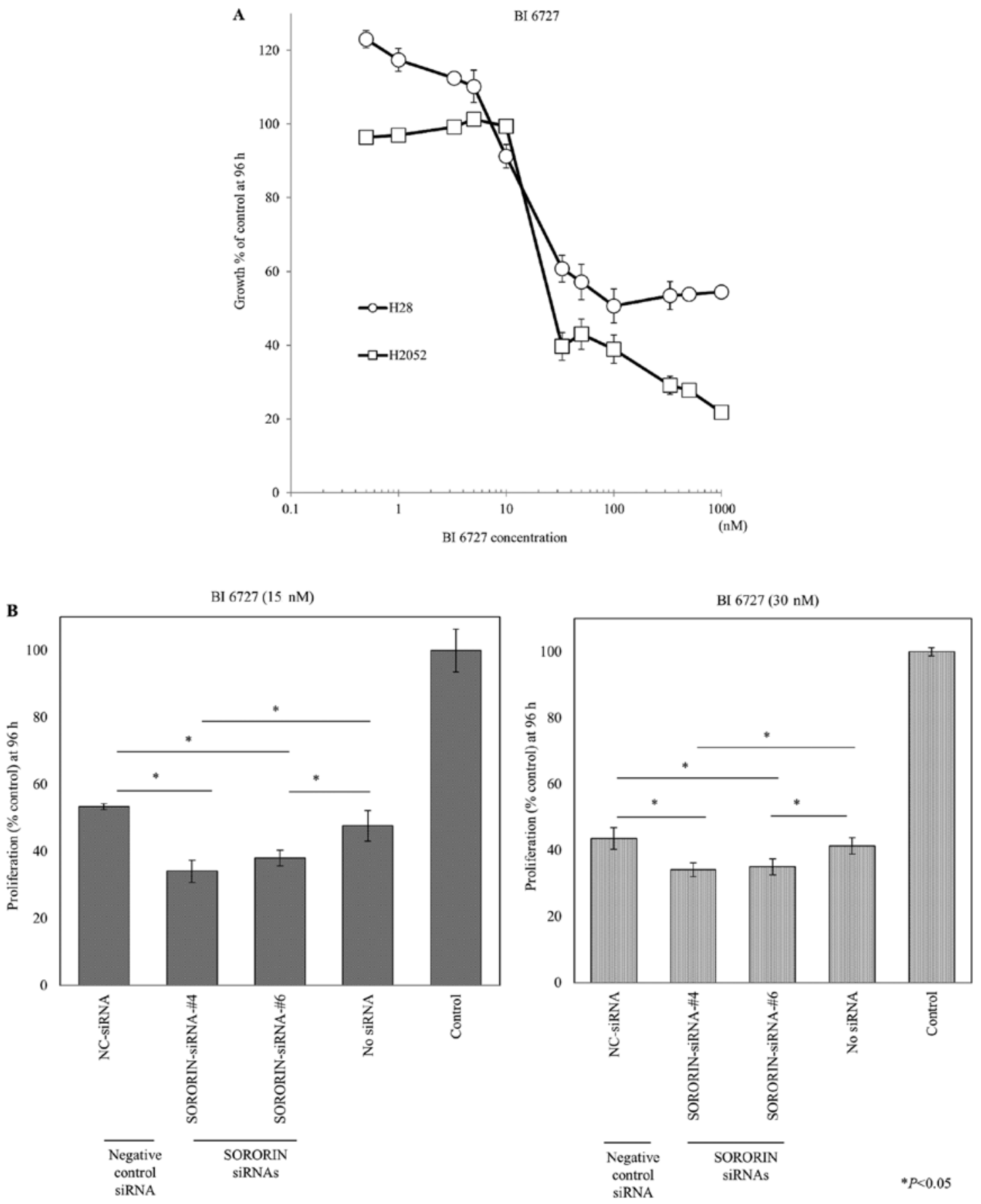

Figure 4. Suppression of SORORIN had combinational growth inhibition of MPM cells with the use of PLK1 inhibitor BI 6727. (A) MPM cell lines were treated with increasing concentrations of BI 6727 and cytotoxic effects were determined at 96 h. (B) H2052 cells were treated with control siRNA or SORORINspecific siRNA (10 nM) under basic use of 15 or $30 \mathrm{nM} \mathrm{BI} 6727$ for $96 \mathrm{~h}$, and then the cell viability was examined. Results shown are mean \pm SD (bars) of four experiments.

we examined curative surgical cases, survival analysis with Kaplan-Meier method indicated that MPM patients with SORORIN-H had shorter overall 5-year survival tendency than those with SORORIN-L ( $\mathrm{P}=0.1664$, by a log-rank test), although this was not statistically significant (Fig. 3B). No significant association was noted between SORORIN expression and other clinicopathological variables in these cases (Table II).

Combined treatment with PLK inhibitor and siRNA against SORORIN shows a combinational growth suppressive effect in cell proliferation in mesothelioma cells. To investigate the effect of PLK inhibitor BI 6727 in mesothelioma cells, we monitored the cell viability of NCI-H28 and H2052 cells treated under various concentrations with BI 6727. Cell growth was significantly reduced in the presence of BI 6727 at concentrations above $10 \mathrm{nM}$ in both cell lines (Fig. 4A); however, cell viability did not decrease at concentrations $>50 \mathrm{nM}$, demonstrating the growth inhibitory effect of BI 6727 in MPM cells. Next, to determine the combinational effect with inhibition of SORORIN and PLK1, we treated MPM cells with both BI 6727 and siRNAs against SORORIN at the same 
time. We confirmed that suppression of SORORIN showed a significantly growth suppressive effect in cell proliferation when combined with BI 6727 in mesothelioma cells (Fig. 4B).

\section{Discussion}

Despite improvements in surgical techniques and adjuvant chemoradiotherapy, MPM still has poor prognosis among malignant tumors. To investigate therapeutic molecular target genes for patients with advanced lung cancer and MPM, we have used qRT-PCR and RNAi-based approach. Through these screenings, we identified six therapeutic candidate genes (KIF11, KIF23, PLK1, NUF2, NDC80 and SORORIN) for the treatment of MPM. PLK1's involvement as SORORIN's interaction protein to regulate MPM cell growth and survival has previously been demonstrated $(17,18)$. These observations support our findings from RNAi-based MPM molecular target screening. We therefore focused on SORORIN and PLK1 axis to further characterize their suitability as therapeutic targets of MPM.

Sororin was initially identified as a substrate of anaphasepromoting (APC) complex and as a regulator of sister chromatid cohesion $(19,20)$. Sororin protein is degraded through APC complex-dependent ubiquitination in the G1 phase, and is required for stable binding of cohesion molecule to chromatid (20). The stabilization of these cohesin complexes depends on Sororin, which prevents premature removal of cohesion from chromatin (21). Sororin also promotes cohesin release from sister chromatid arms in prophase via interaction with Plk1 $(12,22)$. These sororin-containing cohesin rings maintain sister chromatids together during mitosis until cohesin is removed from chromosome arms during prophase and from the centromeric region during the metaphase-to-anaphase transition (28). Physiological regulation of spliceosome function can act as checkpoints to influence cell division or genome stability (21). Overexpression of SORORIN is associated with poor prognosis in NSCLC, and siRNA-mediated knockdown against SORORIN has been shown to inhibit cell proliferation in NSCLC cell lines (23). In this study, we found that SORORIN was overexpressed in majority of MPM samples and inhibition of SORORIN led to suppression of the MPM cell growth. Identification of anticancer drugs that target components of the spliceosome, and mutations or upregulating factors that affect the expression of these components may be relevant in this context (24). Given the importance of splicing and cohesin in cancer and other human diseases $(25,26)$, targeting the SORORIN genes deserve further exploration in future studies.

PLK1 gene plays a crucial role in regulation of cell division at several points during the mitotic phase of the cell cycle, including mitotic entry, bipolar spindle formation, chromosome alignment, segregation of chromosomes and cytokinesis $(27,28)$. PLK1 overexpression is a common event seen in various tumors, such as colorectal cancers (CRCs) (29), head and neck (30) and ovarian cancers (31). Overexpression of PLK1 is also associated with poor prognosis in non-small cell lung cancers (NSCLC) (32), and short interference RNA (siRNA)-mediated knockdown against PLK1 has been shown to inhibit cell proliferation in NSCLC cell lines (33) and also mesothelioma (18). PLK1 should thus be a good candidate for targeted therapy in different types of cancer. In fact, multiple PLK1 inhibitors, including BI 2536 and BI 6727 (volasertib), have been used as a promising target in clinical trials (34-36). However, although several clinical trials of BI 6727 in solid tumors have been performed recently and some patients with solid tumors have responded well to single agent BI 6727, drug-related adverse effects were observed including dose-dependent hematologic toxicity $(37,38)$. Combination therapy is a potential option to improve efficacy, and volasertib combined with platinum chemotherapy was investigated in this context (39). Additional studies in advanced solid tumors are investigating volasertib with other agents combined, including trials involving the kinase inhibitors afatinib and nintedanib with promising antitumor activity $(40,41)$. In this study, we demonstrated that significant growth suppressive effect of the combinational use of SORORIN and PLK1 inhibition. Although further investigation will be needed, we can reduce the dose of PLK1 inhibitor and increase the antitumor activity by combining it with the inhibition of SORORIN.

In conclusion, the present study demonstrates that SORORIN and PLK1, which play crucial roles in tumor growth and cell survival, are highly expressed in MPM. Suppression of SORORIN had combinational growth inhibition of MPM cells when used with PLK1 inhibitor BI 6727, suggesting combination therapy targeting these genes can be a potential new therapeutic strategy for patients with MPMs. The urgent need for novel treatment approaches for MPM is clear. Given our promising findings, further evaluation of these approaches in xenograft models is recommended.

\section{Acknowledgements}

The authors thank Ms. Judy McConnell and Ms. Alexandria Grindlay (Toronto General Hospital) for laboratory management.

\section{References}

1. Yang H, Testa JR and Carbone M: Mesothelioma epidemiology, carcinogenesis, and pathogenesis. Curr Treat Options Oncol 9: 147-157, 2008.

2. Carbone M, Kratzke RA and Testa JR: The pathogenesis of mesothelioma. Semin Oncol 29: 2-17, 2002.

3. Travis WD, Brambilla E, Burke AP, Marx A and Nicholson AG: WHO Classification of Tumours of the Lung, Pleura, Thymus and Heart. 4th edition Volume 7. WHO Press, 2015.

4. Robinson BW and Lake RA: Advances in malignant mesothelioma. N Engl J Med 353: 1591-1603, 2005.

5. Robinson BW, Musk AW and Lake RA: Malignant mesothelioma. Lancet 366: 397-408, 2005.

6. Becklake MR, Bagatin E and Neder JA: Asbestos-related diseases of the lungs and pleura: Uses, trends and management over the last century. Int J Tuberc Lung Dis 11: 356-369, 2007.

7. Vogelzang NJ, Rusthoven JJ, Symanowski J, Denham C, Kaukel E, Ruffie P, Gatzemeier U, Boyer M, Emri S, Manegold C, et al: Phase III study of pemetrexed in combination with cisplatin versus cisplatin alone in patients with malignant pleural mesothelioma. J Clin Oncol 21: 2636-2644, 2003.

8. Zucali PA, De Vincenzo F, Simonelli M and Santoro A: Future developments in the management of malignant pleural mesothelioma. Expert Rev Anticancer Ther 9: 453-467, 2009.

9. Cho BC, Feld R, Leighl N, Opitz I, Anraku M, Tsao MS Hwang DM, Hope A and de Perrot M: A feasibility study evaluating Surgery for Mesothelioma After Radiation Therapy: The 'SMART' approach for resectable malignant pleural mesothelioma. J Thorac Oncol 9: 397-402, 2014. 
10. Kato T, Wada H, Patel P, Hu HP, Lee D, Ujiie H, Hirohashi K, Nakajima T, Sato M, Kaji M, et al: Overexpression of KIF23 predicts clinical outcome in primary lung cancer patients. Lung Cancer 92: 53-61, 2016.

11. Kato T, Lee D, Wu L, Patel P, Young AJ, Wada H, Hu HP, Ujiie H, Kaji M, Kano S, et al: Kinesin family members KIF11 and KIF23 as potential therapeutic targets in malignant pleural mesothelioma. Int J Oncol 49: 448-456, 2016.

12. Zhang N, Panigrahi AK, Mao Q and Pati D: Interaction of Sororin protein with polo-like kinase 1 mediates resolution of chromosomal arm cohesion. J Biol Chem 286: 41826-41837, 2011.

13. Union for International Cancer Control (UICC): TNM Classification of Malignant Tumours. 7th edition. WileyBlackwell, 2009

14. Rizzardi AE, Johnson AT, Vogel RI, Pambuccian SE, Henriksen J, Skubitz AP, Metzger GJ and Schmechel SC: Quantitative comparison of immunohistochemical staining measured by digital image analysis versus pathologist visual scoring. Diagn Pathol 7: 42, 2012.

15. Nagashio R, Sato Y, Jiang SX, Ryuge S, Kodera Y, Maeda T and Nakajima T: Detection of tumor-specific autoantibodies in sera of patients with lung cancer. Lung Cancer 62: 364-373, 2008

16. Nagashio R, Sato Y, Matsumoto T, Kageyama T, Satoh Y, Shinichiro R, Masuda N, Goshima N, Jiang SX and Okayasu I: Expression of RACK1 is a novel biomarker in pulmonary adenocarcinomas. Lung Cancer 69: 54-59, 2010.

17. Kawata E, Ashihara E, Nakagawa Y, Kiuchi T, Ogura M, Yao H, Sakai K, Tanaka R, Nagao R, Yokota A, et al: A combination of a DNA-chimera siRNA against PLK-1 and zoledronic acid suppresses the growth of malignant mesothelioma cells in vitro. Cancer Lett 294: 245-253, 2010.

18. Linton A, Cheng YY, Griggs K, Kirschner MB, Gattani S, Srikaran S, Chuan-Hao Kao S, McCaughan BC, Klebe S, van Zandwijk N, et al: An RNAi-based screen reveals PLK1, CDK1 and NDC80 as potential therapeutic targets in malignant pleural mesothelioma. Br J Cancer 110: 510-519, 2014.

19. Rankin S, Ayad NG and Kirschner MW: Sororin, a substrate of the anaphase-promoting complex, is required for sister chromatid cohesion in vertebrates. Mol Cell 18: 185-200, 2005.

20. Schmitz J, Watrin E, Lénárt P, Mechtler K and Peters JM: Sororin is required for stable binding of cohesin to chromatin and for sister chromatid cohesion in interphase. Curr Biol 17: 630-636, 2007.

21. Valcárcel J and Malumbres M: Splicing together sister chromatids. EMBO J 33: 2601-2603, 2014.

22. Zhang $N$ and Pati D: Sororin is a master regulator of sister chromatid cohesion and separation. Cell Cycle 11: 2073-2083, 2012.

23. Nguyen MH, Koinuma J, Ueda K, Ito T, Tsuchiya E, Nakamura Y and Daigo Y: Phosphorylation and activation of cell division cycle associated 5 by mitogen-activated protein kinase play a crucial role in human lung carcinogenesis. Cancer Res 70: 5337-5347, 2010.

24. Bonnal S, Vigevani L and Valcárcel J: The spliceosome as a target of novel antitumour drugs. Nat Rev Drug Discov 11: 847-859, 2012.

25. Cooper TA, Wan L and Dreyfuss G: RNA and disease. Cell 136: 777-793, 2009.

26. Losada A: Cohesin in cancer: Chromosome segregation and beyond. Nat Rev Cancer 14: 389-393, 2014.
27. van de Weerdt $\mathrm{BC}$ and Medema RH: Polo-like kinases: A team in control of the division. Cell Cycle 5: 853-864, 2006.

28. Barr FA, Silljé HH and Nigg EA: Polo-like kinases and the orchestration of cell division. Nat Rev Mol Cell Biol 5: 429-440, 2004.

29. Takahashi T, Sano B, Nagata T, Kato H, Sugiyama Y, Kunieda K, Kimura M, Okano Y and Saji S: Polo-like kinase 1 (PLK1) is overexpressed in primary colorectal cancers. Cancer Sci 94 : 148-152, 2003.

30. Knecht R, Elez R, Oechler M, Solbach C, von Ilberg C and Strebhardt K: Prognostic significance of polo-like kinase (PLK) expression in squamous cell carcinomas of the head and neck. Cancer Res 59: 2794-2797, 1999.

31. Weichert W, Denkert C, Schmidt M, Gekeler V, Wolf G, Köbel M, Dietel M and Hauptmann S: Polo-like kinase isoform expression is a prognostic factor in ovarian carcinoma. $\mathrm{Br} \mathrm{J}$ Cancer 90: 815-821, 2004.

32. Wolf G, Elez R, Doermer A, Holtrich U, Ackermann H, Stutte HJ, Altmannsberger HM, Rübsamen-Waigmann $\mathrm{H}$ and Strebhardt K: Prognostic significance of polo-like kinase (PLK) expression in non-small cell lung cancer. Oncogene 14: 543-549, 1997.

33. Kawata E, Ashihara E and Maekawa T: RNA interference against polo-like kinase-1 in advanced non-small cell lung cancers. J Clin Bioinforma 1: 6, 2011.

34. Sebastian M, Reck M, Waller CF, Kortsik C, Frickhofen N, Schuler M, Fritsch H, Gaschler-Markefski B, Hanft G, Munzert G, et al: The efficacy and safety of BI 2536, a novel Plk-1 inhibitor, in patients with stage IIIB/IV non-small cell lung cancer who had relapsed after, or failed, chemotherapy: Results from an open-label, randomized phase II clinical trial. J Thorac Oncol 5: 1060-1067, 2010.

35. Ellis PM, Chu QS, Leighl N, Laurie SA, Fritsch H, GaschlerMarkefski B, Gyorffy S and Munzert G: A phase I open-label dose-escalation study of intravenous BI 2536 together with pemetrexed in previously treated patients with non-small-cell lung cancer. Clin Lung Cancer 14: 19-27, 2013.

36. Liu X: Targeting Polo-Like Kinases: A Promising Therapeutic approach for cancer treatment. Transl Oncol 8: 185-195, 2015.

37. Schöffski P, Awada A, Dumez H, Gil T, Bartholomeus S, Wolter P, Taton M, Fritsch H, Glomb P and Munzert G: A phase I, doseescalation study of the novel Polo-like kinase inhibitor volasertib (BI 6727) in patients with advanced solid tumours. Eur J Cancer 48: 179-186, 2012.

38. Stadler WM, Vaughn DJ, Sonpavde G, Vogelzang NJ, Tagawa ST, Petrylak DP, Rosen P, Lin CC, Mahoney J, Modi S, et al: An open-label, single-arm, phase 2 trial of the Polo-like kinase inhibitor volasertib (BI 6727) in patients with locally advanced or metastatic urothelial cancer. Cancer 120: 976-982, 2014.

39. Awada A, Dumez H, Aftimos PG, Costermans J, Bartholomeus S, Forceville K, Berghmans T, Meeus MA, Cescutti J, Munzert G, et al: Phase I trial of volasertib, a Polo-like kinase inhibitor, plus platinum agents in solid tumors: Safety, pharmacokinetics and activity. Invest New Drugs 33: 611-620, 2015.

40. Machiels JP, Peeters M, Herremans C, Surmont V, Specenier P, De Smet M, Pilz K, Strelkowa N, Liu D and Rottey S: A phase I study of volasertib combined with afatinib, in advanced solid tumors. Cancer Chemother Pharmacol 76: 843-851, 2015.

41. de Braud F, Cascinu S, Spitaleri G, Pilz K, Clementi L, Liu D, Sikken $P$ and De Pas T: A phase I, dose-escalation study of volasertib combined with nintedanib in advanced solid tumors. Ann Oncol 26: 2341-2346, 2015. 